\title{
Pengalaman Pasien Mengalami Serangan Jantung Pertama Kali yang dirawat di Ruang CICU
}

\author{
Didi Kurniawan ${ }^{1}$, Kusman Ibrahim ${ }^{2}$, Ayu Prawesti $\mathbf{P}^{2}$ \\ ${ }^{1}$ Universitas Borneo, ${ }^{2}$ Fakultas Keperawatan Universitas Padjajdjaran \\ E-mail: kurniawandik82@gmail.com
}

\begin{abstract}
Abstrak
Serangan jantung merupakan peristiwa terhambatnya aliran darah pada arteri koroneryang menyebabkan ototjantung kekurangan oksigen sehingga terjadi kerusakan irreversibel miokard, reaksi tidak percaya, penolakan, marah, dan takutakan kematian. Serangan jantung pada pasien dapat berdampak pada aspek fisik dan psikologis pasien tersbut dan keluarganya. Staf pelayanan kesehatan termasuk perawat perlu lebih memahami perubahan yang terjadi sepanjang perjalanan hidup pasien yang mengalami serangan jantung pertama kali agar tercapai asuhan keperawatan holistik. Penelitian ini menggunakan metode kualitatif fenomenologis terhadap empat laki-laki dan tiga perempuan yang berusia antara 42-68 tahun melalui wawancara mendalam. Analisis hasil wawancara menggunakan metode Colaizzi. Pengalaman hidup pasien yang mengalami serangan jantung pertama kali dikelompokkan ke dalam tiga tahapan. Tahap pertama yaitu sebelum serangan; situasi yang mencetuskan dan menyebabkan serangan jantung. Tahap kedua yaitu saat terjadi serangan jantung; nyeri dada seperti dihimpit beton, takut meninggal dunia, tidak percaya mengalami serangan jantung, pentingnya kehadiran keluarga saat serangan, dan putus asa mencari pelayanan kesehatan. Tahap ketiga yaitu selama perawatan; merasa sudah sembuh karena tidak nyeri dada lagi, pasrah dan berdoa serta menganggap sakit sebagai cobaan dari Tuhan, keinginan tetap beribadah meskipun sakit, kebahagiaan memeroleh kehidupan ke dua dari Tuhan, gangguan tidur selama perawatan, dan kesulitan pembayaran biaya rumah sakit. Penelitian menemukan wawasan baru yaitu putus asa mencari pelayanan kesehatan, merasa sudah sembuh karena tidak nyeri dada lagi, dan kebahagiaan memeroleh kesempatan hidup kedua dari Tuhan. Berdasarkan hasil temuan maka perlu membuat sistem pertolongan yang cepat pada korban serangan jantung, meningkatkan pemahaman pasien melalui pendidikan kesehatan mengenai serangan jantung yang dialami sehingga tercapai pelayanan yang paripurna.
\end{abstract}

Kata kunci: Koroner, pengalaman, serangan jantung pertama.

\section{Life Experiences of First-Time Heart Attack Patients who are Hospitalised in CICU}

\begin{abstract}
A heart attack is an inhibition of blood flow in the coronary arteries that causes oxygen deficiency to the heart muscles, causing irreversible myocardial damage as well as disbelief, denial, anger, and fear of death in patients. A heart attack affects the physical and psyhological aspects of the patient and their family. This situation requires doctors and nurses to better understand the changes in the lives of patients who have their first heart attack in order to reach holistic nursing care. This study uses qualitative method with phenomenological approach. Data was collected by in-depth interviews with 4 men and 3 women between the age of 42 to 68 . Data were analyzed with Colaizzi method. Life experiences of patients who have their first heart attack are categorised into 3 phases. The first phase is before heart attack occurs, i.e. circumstances that triggered heart attack. The second phase is when heart attack occurs, e.g. chest pain as if being squeezed by a piece of concrete, fear of death, disbelief, the importance of family during the attack, and desperately seeking medical services. The third phase is during treatment, e.g. feeling better because chest pain has subsided, resignation, praying, considering pain as a test from God, the intention to keep practicing religion in spite of being sick, feeling relieved and happy to receive a second chance from God, sleep disorder during treatment, and difficulty to pay hospital costs. This study discovered new forms of life experiences, including desperately seeking medical care, feeling better because chest pain has subsided, and feeling happy to receive a second chance from God. The findings of this study suggest the need for timely medical response for people having a heart attack, increased involvement of family during the treatment of early heart attack, visits from clergy and improved understanding of patients through health education, in order to develop an excellent medical service.
\end{abstract}

Key words: Heart attack, life experience, phenomenology. 
Didi Kurniawan: Pengalaman Pasien Mengalami Gagal Jantung

\section{Pendahuluan}

Serangan jantung merupakan peristiwa terhambatnya aliran darah arteri koroner yang menyebabkan otot jantung kekurangan oksigen sampai terjadi infark (Price \& Wilson, 2013; Setyohadi, Arsana, Suryanto, et al., 2012). Menurut World Health Organization (2008), sindrom koroner akut merupakan penyebab kematian utama di dunia. Terhitung sebanyak 7.200.000 (12,2\%) kematian terjadi akibat sindrom koroner akut. Di Indonesia pada tahun 2008 penyakit infark miokard akut merupakan penyebab kematian pertama dengan angka mortalitas 220.000 (14\%). Data-data tersebut sesuai dengan hasil penelitian yang dilakukan oleh Trotter, Gallagher, dan Donoghue (2011) yang mengungkapkan bahwa penyumbang terbesar angka kematian dan kesakitan akibat penyakit jantung adalah penyakit jantung koroner.

Bahaya serangan jantung yang mengancam nyawa sangat dirasakan oleh pasien yang baru pertama kali mengalaminya. Berdasarkan hasil wawancara kepada beberapa pasien yang mengalami serangan jantung pertama kali pasien mengatakan "....sakitnya seperti ditimpa beton....tidak pernah terfikir kalau saya menderita sakit jantung, sulit dipercaya, seperti disambar petir dan rasanya mau mati saja....". Selain itu, berdasarkan hasil observasi terhadap beberapa pasien yang mengalami serangan jantung pertama kali, pasien terlihat cemas, murung, meringis, dan menangis. Berdasarkan hasil wawancara dan observasi tersebut peneliti mendapatkan fenomena berkaitan dengan kondisi pasien penyakit jantung seperti mengeluh nyeri yang luar biasa, rasa tidak percaya atau penolakan mengalami penyakit jantung, kepasrahan kepada Tuhan, dan kebutuhan pasien akan pendampingan keluarga dan orang terdekat.

Serangan jantung merupakan kondisi kegawatdaruratan paling mendesak yang membutuhkan diagnosis dan penanganan tepat dan cepat untuk menyelamatkan jantung dari kerusakan yang lebih parah (Douglas, 2005; Grech \& Ramsdale, 2003). Prioritas utama dalam penatalaksanaan medis dan keperawatan adalah aspek fisik dengan menyelamatkan kehidupan pasien (Morton, Fontaine, Hudak, \& Gallo, 2012;
Anderson, Adams, Antman, et al., 2007). Kondisi kegawatdaruratan fisik yang telah teratasi harus dilanjutkan dengan pelayanan keperawatan yang bersifat holistik karena pasien dengan serangan jantung pertama kali mengalami kondisi kritis yang penuh stres dan gangguan emosional sehingga membutuhkan dukungan keluarga dan profesional kesehatan (Laberge, 2012; Jeff, Christopher, \& James, 2010; Thomas \& Alexander, 2010). Boersma, Maes, dan Joekes (2005) mengungkap bahwa partisipan dengan serangan jantung pertama kali mengalami stres yang tinggi.

Permasalahan psikososial yang tidak teratasi dapat beranjut menjadi depresi yang dapat menimbulkan keinginan bunuh diri sehingga meningkatkan morbiditas dan mortalitas akibat penyakit jantung (Zhao, Luo, Wang, \& Su, 2008; Dickens, Percival, Mcgowan, et al., 2004). Hal tersebut dapat disebabkan oleh adanya perbedaan budaya, spiritualitas, dan mekanisme koping yang positif yang digunakan oleh partisipan. Wang, Thompson, Chair, et al. (2008) mengungkapkan bahwa pengalaman pasien yang mengalami serangan jantung pertama kali sampai masa pemulihan awal berbedabeda karena dipengaruhi oleh tradisi budaya.

Pasien yang mengalami serangan jantung pertama kali akan menghadapi tahapan peristiwa mulai dari saat serangan, proses perawatan dan pengobatan. Selama tahapan peristiwa tersebut pasien mengalami situasi kritis dan penuh stres yang mengancam kehidupannya sehingga sangat berpengaruh terhadap kondisi fisik maupun psikososial pasien (Suryani, 2012; Urden, et al., 2010). Urutan kejadian selama proses tersebut merupakan sebuah riwayat yang bisa diceritakan secara rinci dan mendalam sebagai pengalaman hidup sehingga peneliti tertarik memperoleh pandangan yang lebih mendalam meliputi aspek biologis atau fisik, psikologis, sosial, dan spiritual, serta perspektif tentang pengalaman pasien saat mengalami serangan jantung pertama kali. Hasil penelitian ini diharapkan mampu membantu perawat, dan tenaga kesehatan lain untuk memahami pengalaman pasien yang mengalami serangan jantung pertama kali dalam menghadapi perubahan dan dampak yang terjadi sehingga dapat tercapai perawatan yang holistik sesuai dengan 
Didi Kurniawan: Pengalaman Pasien Mengalami Gagal Jantung

falsafah keperawatan.

\section{Metode Penelitian}

Penelitian kualitatif fenomenologis ini melibatkan 7 informan (4 laki-laki; 3 perempuan), berusia antara 42 sampai 68 tahun yang dipilih menggunakan teknik purposive sampling. Pengumpulan data dilakukan menggunakan wawancara mendalam (in-depth interview) dengan direkam menggunakan voice recorder. Analisis hasil wawancara menggunakan metode analisis Colaizzi (Wojar \& Swanson, 2007; Sanders, 2003).

\section{Hasil Penelitian}

Pengalaman pasien mengalami serangan jantung pertama kali mencakup 12 tema yang dikelompokkan berdasarkan tahap kejadian yang dialaminya. Tahap pertama yaitu sebelum terjadi serangan, tahap kedua yaitu saat terjadi serangan jantung, dan tahap ketiga yaitu selama perawatan.

1. Tahap sebelum serangan jantung

Tema yang ditemukan pada tahap ini adalah situasi yang mencetuskan dan menyebabkan serangan jantung. Serangan jantung terjadi ketika sedang beraktifitas, seperti yang diungkapkan oleh partisipan dua;

"......biasanya saya naik turun tangga itu bolak balik berapa kali juga ga sesak nafas, tapi kemaren itu dada saya langsung sakit dan sesak sekali.....".

Berbeda dengan partisipan dua, partisipan empat dan tujuh mengungkapkan karena mereka sedang banyak pikiran atau stres yang disebabkan masalah pekerjaan maupun masalah dalam keluarga.

Berikut pernyataan partisipan:

"....mungkin karena banyak pikiran, trus bapakjuga suka merokok.....” (Partisipan 4). “....saya orangnya ga suka bercerita dengan orang lain tentang kesusahan.... pokokna mah kalau punya masalah saya pendam aja dalam hati..." (P 7).

Selain faktor pencetus, juga terungkap faktor risiko penyebab serangan jantung yaitu kebiasaan merokok, minum kopi, dan tekanan darah tinggi. Seperti yang diungkapkan oleh partisipan berikut:

".....y a emang ibu punya kebiasaan merokok sejak SMA dulu sampai kemaren sebelum serangan ini ibu masih merokok...." (P1)

".....kalau malam saya suka duduk sendiri, bikin kopi, bikin merokok, namanya orang lagi banyak masalah ya gimana lagi...." (P7). “.......bapak tahu kena darah tinggi lima tahun yang lalulah saat berobat ke puskesmas... orang tua bapak juga mengalami darah tinggi...." (P 4)

2. Tahap ketika terjadi serangan jantung

Pada tahap ini ditemukan tema pertama yaitu nyeri dada seperti dihimpit benda berat. Seperti pernyataan beberapa partisipan berikut ini:

“....pokoknya sakit, dipegang sakit, sakit sekali kayak ditimpa benda berat dan baru kali ini saya alami..." (P 1)

“......pokoknya luar biasa sakitlah, seperti ditekan dan dihimpit beton, jadi dada terasa sempit gitu....." (P 5)

Selain itu nyeri dada juga dirasakan partisipan menjalar sampai bahu kiri disertai keringat dingin, seperti yang dinyatakan partisipan berikut ini:

“......pokoknya panas sekali sampai leher depan sini... dan belakang di bagian ini... sampai keluar panas dingin menahan sakit itu......" (P 3).

Tema kedua yaitu takut meninggal dunia yang disebabkan oleh nyeri dada yang luar biasa seperti dihimpit beton, dada terasa sesak, menjalar ke bahu sampai punggung dan berlangsung selama lebih dari 30 menit. Berikut pernyataan partisipan:

“...takut dan paniklah kalo meninggal saat itu...." (P 1).

“.....yang terpikir saat itu mah cuma takut aja kalo meninggal...”(P 4).

Tema ketiga yaitu tidak percaya mengalami serangan jantung. Partisipan yang mengalami serangan jantung pertama kali memiliki respon tidak percaya, terkejut, bingung, dan merasa sedih, seperti terungkap pada pernyataan berikut:

“.....saat itu saya sangat tidak percaya kena 
Didi Kurniawan: Pengalaman Pasien Mengalami Gagal Jantung

serangan jantung, saya pikir mah sakit dada biasa, karena saya kan engga merokok......" (P 5)

“.....ya kaget, sedih juga harus sakit kayak gini, ibu kan rajin kerja dan ga pernah sakit dada juga sebelumnya....." (P 6)

Tema keempat yaitu pentingnya kehadiran keluarga saat serangan jantung, hal tersebut sangat dirasakan partisipan seperti terungkap pada pernyataan berikut:

"......kalo ga ada keluarga yang bantu ibu saat serangan jantung, mungkin ibu ga sampe disini...." (P 1)

“....untungnya saat kejadian ada keluarga yang tau, merekalah yang membantu dan membawa bapak kesini....” (P 2)

Tema kelima yaitu keputusasaan mencari pelayanan kesehatan. Tempat tinggal partisipan yang jauh dari fasilitas pelayanan kesehatan membuat sebagian besar partisipan kesulitan mengakses pelayanan kesehatan dengan cepat dan tepat sehingga menimbulkan keputusasaan dalam mencari pelayanan kesehatan. Seperti yang terungkap pada pernyataan partisipan berikut ini:

"....ibu sudah pasrah, sudah putus asa kenapa teh nasib ibu mengalami serangan jantung seperti ini....apa karena ibu orang miskin jadi ga ada yang mau nolong ibu atau apa la hebabnya ini teh... jadi dimobil itu teh ibu sedih, takut umur ibu ga sampai...."(P 6). ".....saya dah ga punya harapan kenapa teh harus dipindah gitu, apa pada ga mau nolong orang miskin atau gimanalah gitu......katanya berobat gratis, tapi ga mau menolong orang kayak saya ini, mungkin mau biarkan saya mati apa ya...." (P 7).

\section{Tahap selama perawatan di rumah sakit} Pengalaman partisipan selama tahap ini terungkap enam tema yang diuraikan sebagai berikut:

Tema pertama yaitu merasa sudah sembuh karena tidak nyeri dada lagi. Persepsi partisipan bahwa dirinya telah sembuh dari rasa sakit dan menganggap sudah tidak ada keluhan berarti sudah sehat membuat partisipan merasakan kesepian, bosan, dan ingin cepat pulang. Padahal nyeri dada yang sudah berkurang bukan berarti penyakit jantung yang diderita partisipan sudah sembuh, karena masih harus menjalani terapi pengobatan dan rehabilitasi. Berikut pernyataan partisipan:

".....ibu ngerasa udah sembuh.....dah ga sakit lagi jadi ibu pengen pulang, tapi belum boleh...." (P I)

“......bapak tidak merasakan nyeri lagi, sudah sembuh, kalo boleh sih pengen cepet pulang, lama-lama disini bosan juga....." (P 2)

Tema kedua yaitu pasrah dan berdoa serta menganggap sakit sebagai cobaan dari Tuhan. Partisipan memiliki sikap pasrah, tawakal, tenang, sabar, berusaha berobat dan berdoa kepada Tuhan atas apa yang dialami. Berikut merupakan pernyataan partisipan:

"......kalau saya menganggap semua ini sebagai cobaan dari Alloh, ya semoga bapak kuat dalam menjalani cobaan ini....." (P 4)

".......kalau sekarang mah cuma bisa berdoa, pasrah weh, semoga bisa sembuh dan bisa kerja lagi...." (P 7)

Tema ketiga yaitu keinginan tetap beribadah meskipun sakit. Partisipan memiliki keinginan melaksanakan ibadah saat sakit untuk mendekatkan diri pada Tuhan, tetapi tidak tahu bagaimana cara melaksanakannya. Seperti pernyataan partisipan berikut ini: “....selama disini belum ada sholat, karena ga tau caranya, belum bisa wudhu juga.... ga pernah ditanya atau disuruh buat sholat, paling juga suka diingetin banyak doa ya bu biar cepat sembuh, gitu weh...." (P 7).

Tema keempat yaitu kebahagiaan memperoleh kehidupan kedua dari Tuhan. Partisipan mengungkapan rasa bahagia dan syukur karena masih diberikan kesempatan hidup oleh Tuhan setelah melalui peristiwa yang mengancam kehidupannya. Seperti terungkap pada pernyataan berikut:

".....ibu teh seneng pisan, ga nyangka weh... masih bisa hidup sampai hari ini, waktu itu kan jauh dikebun, sempat pingsan trus juga susah dapat rumah sakitnya...." (P 6)

Tema kelima yaitu gangguan tidur selama perawatan. Partisipan sering terbangun ketika tidur malam hari maupun siang hari. Hal tersebut disebabkan tempat tidur sempit dan keras, suhu ruangan yang dingin, terkadang masih merasa nyeri dada, kekhawatiran tidak 
Didi Kurniawan: Pengalaman Pasien Mengalami Gagal Jantung

bisa sembuh dari sakit, dan takut meninggal dunia. Berikut pernyataan partisipan:

“...kalau yang tadi malam tiba-tiba aja terbangun, mungkin karena kedinginan, ruang ini kan kalau malam dingin kali nih." (P 5)

"...tidur malam ibu kadang kebangun sampe dua atau tiga kali, trus debar-debar dadanya...ngerasa khawatir ibu ga bisa sembuh lagi...." (P 6)

Tema keenam yaitu kesulitan pembayaran biaya rumah sakit. Partisipan merasa kesulitan dalam mencukupi kebutuhan pembiayaan selama perawatan karena melakukan pembayaran sendiri dan tidak ditanggung asuransi. Berikut beberapa pernyataan partisipan terkait hal tersebut.

".....masih bayar pribadi, dikumpulkan dari anak-anak dan saudara juga... ibu stres juga ya mendengar obat yang disuntik itu kan mahal, katanya lima juta lebih, belum lagi yang disuntik tiap hari disini..." (P 1).

“....biaya ditanggung bersama-sama karena bapak kan ga ikut asuransi, ya bagaimanalah lagi orang bapak sudah tua.." (P 2)

\section{Pembahasan}

Pembahasan tema disajikan berdasarkan tiga tahap kejadian yang dialami partisipan.

1. Tahap sebelum terjadi serangan

Tahap ini membahas tema tentang situasi yang mencetuskan dan menyebabkan serangan jantung. Penelitian ini mengungkap bahwa sebagian besar partisipan rutin melakukan aktifitas fisik berupa pekerjaan sehari-hari baik aktifitas berat maupun ringan. Serangan jantung yang terjadi pada sebagian besar partisipan yaitu ketika sedang melakukan kegiatan sehari-hari. Selain itu terdapat beberapa partisipan mengalami serangan jantung dalam kondisi istirahat dan terjadi pada pagi hari. Faktor lain yang berpengaruh terhadap terjadinya serangan jantung adalah faktor emosional atau stres yang sering dirasakan oleh partisipan.

Penelitian ini menemukan bahwa sebagian besar partisipan merupakan perokok aktif dan mengkonsumsi minuman kopi sampai terjadinya serangan jantung. Perilaku kesehatan negatif tersebut dilakukan selama puluhan tahun yang telah menjadi kebiasaan sehari-hari partisipan. Menurut partisipan awalnya merokok karena stres dan terbawa lingkungan tempat berkumpul yang sebagian besar perokok sehingga partisipan ikut-ikutan merokok. Partisipan merupakan perokok aktif yang menghabiskan lebih dari satu bungkus rokok sehari, sehingga memiliki faktor risiko primer terjadinya serangan jantung.

Dickens, Cherrington, dan McGowan (2012) mengungkap bahwa masalah stres pada pasien miokard infark biasanya berkaitan dengan tekanan sosial dan perilaku kesehatan negatif seperti merokok. Hal tersebut dapat meningkatkan risiko terjadinya serangan jantung atau memperburuk prognosisnya. Asap rokok banyak mengandung nikotin yang memacu pengeluaran zat adrenalin sehingga meningkatkan tekanan darah. Asap rokok juga mengandung karbon monoksida yang lebih kuat dalam mengikat oksigen dari pada hemoglobin sehingga menurunkan kapasitas penyerapan oksigen yang akan didistrubusikan keseluruh jaringan tubung termasuk jantung. Oleh karena itu perokok aktif yang mengkonsumsi lebih dari 20 batang perhari memiliki risiko enam kali lipat serangan jantung atau infark miokard dibandingkan perokok pasif (Rodriguez, 2009; Avanzas, Espliguero, Sales, et al., 2004).

\section{Tahap ketika terjadi serangan}

Pengalaman partisipan pada tahap ini terungkap lima tema yang peneliti bahas sebagai berikut:

a. Nyeri dada seperti dihimpit benda berat Nyeri yang dirasakan memiliki ciri khas tersendiri dan berbeda dengan nyeri pada umumnya yaitu nyeri dada luar biasa seperti ditimpa atau dihimpit benda berat, seperti kulit yang disayat-sayat pisau, nyeri menjalar sampai ke leher, bahu kiri dan punggung yang berlangsung selama lebih dari 30 menit. Keluhan nyeri dada tersebut sesuai dengan penelitian lain dan beberapa konsep yang dikemukakan oleh Price dan Wilson (2013), Morton, Fontaine, Hudak, dan Gallo (2012). Jerlock, Johansson, dan Danielson (2005) meneliti tentang pengalaman hidup dengan nyeri dada menggunakan metode kualitatif dengan wawancara terbuka dan analisis isi. Hasilnya mengungkap bahwa nyeri yang 
Didi Kurniawan: Pengalaman Pasien Mengalami Gagal Jantung

dialami partisipan benar - benar menyakitkan seperti tekanan, meremukkan seperti kram dan para partisipan tidak memiliki penjelasan rasional untuk rasa sakit mereka.

\section{b. Takut meninggal dunia}

Penelitian ini menemukan perubahan psikologis yang terjadi pada saat partisipan mengalami serangan jantung pertama kali berupa takut meninggal dunia. Menurut Urden, Stacy, dan Lough (2010) kondisi pasien yang mengalami penyakit akut atau dalam kondisi yang dipersepsikan pasien sebagai kondisi yang penuh stres, maka akan menimbulkan kecemasan. Kanel, Hari, Schmid, et al. (2011) juga mengungkap bahwa kecemasan pada pasien SKA timbul karena adanya perasaan takut akan datangnya kematian dan merasa tidak berdaya akibat dari nyeri hebat yang dialami.

c. Tidak percaya mengalami serangan jantung Sebagian besar partisipan terkejut dan tidak percaya telah mengalami serangan jantung, selain itu partisipan juga bingung dan merasa sedih kenapa menderita penyakit jantung. Bass \& Mayou (2002) dalam penelitiannya juga mengungkapkan bahwa mayoritas pasien takut memiliki penyakit jantung dan $50 \%$ pasien tidak menerima didiagnosis mengalami infark miokard akut. Menurut Smith dan Segal (2014) sikap tidak percaya dan kesedihan merupakan respon awal emosional yang alami terhadap kerugian, seperti kehilangan status kesehatan.

d. Pentingnya kehadiran keluarga saat serangan jantung

Peristiwa serangan jantung merupakan suatu kejadian yang tiba-tiba dan sangat dirasakan partisipan sebagai suatu ancaman kehidupan, sehingga pada saat seranganjantung partisipan sangat mengharapkan adanya keluarga yang mendampingi dan memberikan pertolongan dengan cepat. Dukungan keluarga merupakan suatu hal yang sangat penting bagi partisipan dalam menghadapi situasi kritis (Miller, 1999).

e. Putus asa mencari pelayanan kesehatan Beberapa faktor yang menjadi penyebabnya adalah lokasi rumah sakit yang jauh dari tempat tinggal partisipan, fasilitas rumah sakit di daerah yang masih kurang memadai terkait penyakit jantung, kesulitan transportasi menuju rumah sakit, kurangnya penjelasan yang diterima partisipan terkait penyakit yang dialami sehingga tidak dapat dirawat di rumah sakit tersebut. Menurut Laberge (2012) fasilitas kesehatan yang sulit dijangkau warga pedesaan sangat memengaruhi tingkat keberhasilan dari proses rehabilitasi yang dijalani oleh pasien pasca serangan jantung. Undang-undang nomor 44 tahun 2009 tentang rumah sakit pasal tiga juga menyebutkan bahwa rumah sakit harus mempermudah akses masyarakat untuk mendapatkan pelayanan kesehatan, oleh karena itu sudah menjadi kewajiban pemerintah untuk memberikan kesejahteraan terutama kesehatan bagi warga masyarakatnya.

\section{Tapah selama perawatan di rumah sakit} Pengalaman partisipan selama perawatan di rumah sakit terungkap enam tema sebagai berikut:

a. Merasa sudah sembuh karena tidak nyeri dada lagi

Partisipan yang sudah tidak merasakan nyeri dada lagi merasa bahwa dirinya sudah sembuh dari sakit. Kondisi tersebut merupakan persepsi yang keliru karena pada dasarnya pasien memasuki fase kronis dari penyakit jantung yang mereka alami.

Anggapan bahwa telah sembuh dari sakit yang menimbulkan perasaan kesepian dan bosan, sangat berkaitan dengan rata-rata tingkat pendidikan dan usia partisipan, hal tersebut sesuai dengan penelitian Indrawati (2014) yang mengungkap bahwa terdapat hubungan antara pengetahuan dengan tingkat pendidikan pada pasien yang mengalamai sindrom koroner akut dalam memahami penyakit yang dialaminya. Ikram, dkk (2012) juga mengungkap perlunya pendidikan kesehatan pada pasien yang mengalami penyakit jantung tentang kondisi penyakitnya yang disampaikan secara benar.

b. Pasrah dan berdoa serta menganggap sakit sebagai cobaan dari Tuhan

Penelitianinimengungkappartisipanmemiliki keyakinan kepada Tuhan atas apa yang telah mereka alami sehingga dapat bersikap pasrah atau berserah diri dan menganggap serangan jantung yang dialaminya sebagai cobaan dari 
Didi Kurniawan: Pengalaman Pasien Mengalami Gagal Jantung

Tuhan agar mereka hidup lebih baik lagi. Selain itu dengan berserah diri kepada Tuhan partisipan merasa lebih tenang dan lebih cepat bisa menerima keadaannya saat ini.

Menurut Nur'aeni, Ibrahim, dan Agustina (2013) makna spiritualitas pada penderita SKA adalah menerima penyakit sebagai suatu teguran atau cobaan demi hidup yang lebih baik, pasrah kepada Tuhan dengan meningkatkan ibadah dan memohon ampunanNya, serta tetap bersyukur dan memelihara harapan untuk sembuh. Selain itu spiritualitas merupakan salah satu sumber koping yang dapat digunakan dalam beradaptasi terhadap stresor dan merupakan sumber koping yang sangat baik bagi pasien dengan penyakit terminal (Kociszewski, 2004; Quigley, 2002).

c. Keinginan tetap beribadah meskipun sakit Kociszewski (2004) menjelaskan bahwa spiritualitas adalah segala sesuatu yang berkaitan tentang hubungan manusia dengan Tuhannya. Hawari (2004) menjelaskan bahwa media berhubungan dengan Tuhan salah satunya adalah dengan melaksanakan ibadah Sholat. Seluruh partisipan beragama islam yang memiliki salah satu kegiatan ibadah berupa sholat. Selama perawatan partisipan terkadang tidak melaksanakan ibadah sholat karena tidak tahu cara melaksanakannya ketika sakit. Selain itu partisipan hanya diingatkan untuk tetap semangat, sabar dan banyak berdoa dalam menerima kondisi penyakit yang diderita, dan tidak diingatkan atau dibimbing untuk melaksanakan sholat. Kondisi tersebut dapat menimbulkan spiritual distres bagi partisipan yang mengalami serangan jantung sehingga dapat memperburuk kondisi kesehatannya.

Carpenito (2009) mengungkap bahwa hospitalisasi pada pasien dengan serangan jantung dapat menyebabkan spiritual distres karena diagnosis penyakit, adanya kelemahan pada fisik, adanya rasa nyeri, prosedur pengobatan yang harus diisolasi dari dunia luar, serta ketidakmampuan dalam melakukan ritual keagamaan yang biasanya dilakukan secara mandiri. Penelitian ini mengungkap bahwa partisipan memiliki harapan pada perawat agar senantiasa mengingatkan untuk beribadah khususnya sholat, bila perlu membantu dan membimbing partisipan dalam pelaksanaan ibadah.

d. Kebahagiaan memperoleh kesempatan hidup kedua dari Tuhan

Pesan luar biasa disampaikan oleh partisipan bahwa betapa bahagianya mereka masih hidup setelah mengalami suatu peristiwa kritis mengancam kehidupannya. Partisipan bersyukur atas kesempatan umur yang diperolehnya. Perasaan tersebut berkaitan dengan spiritualitas beragama islam sehingga selalu mensyukuri atas apa yang mereka terima. Menurut Rahmawati (2012) dan Ehrlich (2011) perasaan tersebut dipengaruhi salah satunya oleh faktor spiritualitas partisipan, dimana spritualitas juga dipengaruhi oleh faktor usia, agama, kebudayaan dan kepercayaan.

Mayoritas partisipan yang beragama Islam juga selalu diajarkan untuk bersyukur dengan apapun yang dialaminya, karena rencana Tuhan pasti lebih baik daripada rencana hambaNya. Hal tersebut juga sering menjadi ungkapan sehari-hari yang sering kita dengar pada masyarakat Indonesia pada umumnya yaitu selalu merasa beruntung, yang artinya bahwa melihat sisi positif dari suatu kejadian akan menjadikan kita merasa lebih baik dan merupakan koping yang positif (Smith \& Segal, 2014).

\section{e. Gangguan tidur selama perawatan}

Faktor yang memengaruhi gangguan tidur berasal dari faktor internal dan eksternal. Faktor internal yang dirasakan partisipan antara lain masih merasa takut kalau harus meninggal dan terkadang nyeri masih ada. Partisipan mengungkapkan faktor eksternal yang berasal dari lingkungan perawatan berupa suhu ruangan yang terlalu dingin dan tempat tidur kurang nyaman.

Menurut El-Mokadem (2003) partisipan yang mengalami serangan jantung pertama kali mereka sering mengeluhkan gangguan tidur. Perubahan pola tidur tersebut termasuk insomnia, bangun merasa lelah, dan lelah di pagi hari sehingga partisipan sering tidur siang karena merasa tidur dimalam hari kurang terpenuhi. Jeff, Christopher, James (2010) dan James, Theodore, Richard, et al. (2000) mengungkap bahwa terbangun dimalam hari, kelelahan, konsentrasi berkurang, dan gangguan suasana hati mulai dari ringan sampai berat yang dialami oleh 
Didi Kurniawan: Pengalaman Pasien Mengalami Gagal Jantung

penderita serangan jantung merupakan gelaja adanya depresi.

f. Kesulitan pembayaran biaya rumah sakit Permasalah ekonomi yang dirasakan partisipan adalah kesulitan memperoleh uang untuk pembayaran biaya perawatan dan biaya-biaya lain selama dirawat di rumah sakit. Penelitian ini menemukan beberapa partisipan melakukan pembayaran biaya rumah sakit sendiri dan bukan ditanggung oleh asuransi maupun jaminan kesehatan lainnya. Partisipan merasa stres dan bingung harus mencari uang dari mana untuk mencukupi pembiayaan selama dirawat.

Menurut Alter, Naylor, dan Austin (1999) mengungkapkan bahwa angka mortalitas penderita penyakit jantung iskemik lebih tinggi terjadi pada golongan ekonomi rendah jika dibandingkan dengan golongan ekonomi tinggi. Kondisi tersebut sesuai dengan hasil penelitian Dickens, Percival, Mcgowan, et al. (2004) yang mengungkap bahwa faktor risiko depresi pada pasien dengan serangan jantung antara lain usia masih muda, jenis kelamin perempuan, riwayat psikiatri masa lalu, kurangnya dukungan sosial, dan kesulitan ekonomi.

\section{Simpulan}

Pengalaman hidup pasien yang mengalami serangan jantung pertama kali terungkap 12 tema yang dikelompokkan berdasarkan tahap kejadian yang dialaminya. Penelitian ini menemukan wawasan baru berupa putus asa mencari pelayanan kesehatan, merasa sudah sembuh karena tidak nyeri dada lagi, dan kebahagiaan memperoleh kesempatan hidup kedua dari Tuhan setelah melalui situasi kritis yang mengancam kehidupannya. Hasil penelitian ini dapat dijadikan pembelajaran terutama bagi perawat agar semakin meningkatkan empati terhadap pasien yang mengalami serangan jantung sehingga dapat tercapai asuhan keperawatan yang holistik.

\section{Daftar Pustaka}

Alter, D.A., Naylor, C.D., \& Austin, P. (1999). Effects of socioeconomic status on access to invasive cardiac procedures and on mortality after acute myocardial infarction. $N$ Engl $J$ Med. 341(18), 1359-67.

Anderson, J.L., Adams, C.D., Antman, E.M., Bridges, C.R., \& Califf, R.M. (2007). ACC/ AHA 2007 guidelines for the management of patients with unstable angina/non-stelevation myocardial infarction. $\mathrm{J}$ am Coll Cardiol. 50, e1-e157.

Avanzas, P., Espliguero, A., Sales, J.C., Aldama, G., Pizzi, C. et al. (2004). Markers of inflammation and multiple complex stenoses (pancoronary plaque vulnerability) in patients with non-ST segment elevation acute coronary syndromes. Heart \& Lung . 90, 847-52.

Bass \& Mayou (2002). Depression and anxiety as predictors of outcome after myocardial infarction. Psychosomatic Medicine 62, 212-219.

Boersma, S., Maes, S., \& Joekes, K. (2005). Goal disturbance in relation to anxiety, depression, and health-related quality of life after myocardial infarction. Qual Life Res.14, 2265-2275.

Carpenito, L.J., (2009). Diagnosis keperawatan aplikasi pada praktik klinis. Alih bahasa: Kadar, K.S., Evriyani, D., Yudha, E.K., Ester, M., Edisi 9. Jakarta: EGC.

Dickens, C.M., Percival, C., Mcgowan, L., Douglas, J., Tomenson, B., Cotter, L., et al. (2004). The risk factors for depression in first myocardial infarction patients. Psychological Medicine, 34, 1083-1092.

Douglas, M., (2005). The pathophysiology of acute coronary syndromes. Washington University School of Medicine. p1-p6.

Ehrlich (2011). Spirituality: overview. University of Maryland Medical System. Diakses pada tanggal 20 Desember 2014 dari : http://umm.edu/health/medical/ altmed/ treatment/spirituality.

El-Mokadem, N.M., (2003). The relationships between fatigue, depression, and sleep 
Didi Kurniawan: Pengalaman Pasien Mengalami Gagal Jantung

disturbance after myocardial infarction. ProQuest Dissertations and Theses.

Grech, ED., \& Ramsdale, DR., (2003). Acute coronary syndrome: unstable angina and nonST segment elevation myocardial infarction. BMJ. 326,(7401):1259-61.

Hawari, D., (2004). Penyakit jantung koroner dimensi psikoreligi. Jakarta: Balai penerbit FKUI.

Ikram (2012). Pengaruh health education terhadap tingkat kecemasan pada pasien yang akan menjalani percutaneous coronary interventions (PCI) di RSUP Dr. Hasan Sadikin Bandung. Tesis. Tidak dipublikasikan.

Indrawati, L., (2014). Hubungan antara pengetahuan, sikap, persepsi, motivasi, dukungan keluarga dan sumber informasi pasien penyakit jantung koroner dengan tindakan pencegahan sekunder faktor risiko (studi kasus di RSPAD Gatot Soebroto Jakarta). Jurnal Ilmiah WIDYA, 2 (3), 30-36.

James L, Theodore A, Richard C, \& Roman W. (2000). The influence of anxiety and depression on outcomes of patients with coronary artery disease. American Medical Association. 160, 1913-1919.

Jeff, C., Christopher, M., \& James, L., (2010). The relationship between depression, anxiety and cardiovascular outcomes in patients with acute coronary syndromes. Neuropsychiatric Disease and Treatment. 64, 15-28.

Jerlock, M., Johansson, M.G., \& Danielson, E. (2005). Living with unexplained chest pain. Journal of Clinical Nursing, 14, 956964.

Kanel, R., Hari, R., Schmid, J.P., Saner, H., \& Bergre, S. (2011). Distres related to myocardial infraction and cardiovascular outcome: a retrospective observational study. Biomedicine Central Psychiatry, 11, 98.

Kociszewski. (2004). Spiritual care: a phenomenologic study of critical care nurses. Heart Lung. 33(6), 401-11.
Laberge, C.G. (2012). The lived experience of heart attack: individual accounts of primary percutaneous coronary intervention survivors. ProQuest Information and Learning Company. Umi number: 3503952.

Miller, R.A (1999). The Experience of Chest Pain in Adult Post-Cardiac Transplant Recipients. UMI Company. ProQuest Dissertations and Theses.

Morton, P.G., Fontaine, D.K., Hudak, M.C., \& Gallo, B.M., (2012). Keperawatan kritis pendekatan asuhan holistik. Edisi 8 Volume 1. Alih bahasa: Subekti BD, et al., Editor: Ariani, et al. Jakarta: EGC.

Nur'aeni, A., Ibrahim, K., \& Agustina, H.R. (2013). Makna Spiritualitas pada Klien dengan Sindrom Koroner Akut. Jurnal Keperawatan Padjadjaran, 1(2), 79-87.

Price, S. A., \& Wilson, L.M., (2012). Patofisiologi : konsep klinis proses-proses penyakit, $6 \mathrm{ed}$. vol. 1. Alih bahasa : Pendit BU, et al. Editor : Hartanto, H., et al. Jakarta: EGC.

Quigley MP., (2002). Female coping with cardiac rehabilitation after a cardiac event a qualitative study. Proquest information and learning company. Umi number: 3053117.

Rahmawati,SW.,(2012). Roleofreligiousness/ spirituality in resilience of fisheries college cadets. Journal of educational, health and community psychology, 3(1), 31-40.

Sanders, C., (2003). Application of colaizzi method: interpretation of an auditable decision trail by a novice researcher content management. Contemporary Nurse. 14, 292302.

Setyohadi, B., Arsana, PM., Suryanto, A., Soeroto, AY., \& Abdullah, M., (2012). EIMED PAPDI kegawatdaruratan penyakit dalam. Buku 1. Jakarta: Interna Publishing.

Smith, M. \& Segal, J. (2014). Introduction to Grief and Bereavement Issues. Diakses pada 12 November 2014 dari http://www. helpguide.org/articles/grief-loss/coping- 
Didi Kurniawan: Pengalaman Pasien Mengalami Gagal Jantung

with-grief-and-loss.htm.

Suryani (2012). Aspek psikososial dalam merawat pasien kritis. Diakses pada tanggal 15 Mei 2015 dari http://pustaka.unpad.ac.id/ wp-content/uploads/2015/04/13-AspekPsikososial1.pdf.

Thomas, J., \& Alexander, H., (2010). The american heart association science advisory on depression and coronary heart disease: an exploration of the issues raised. Cleveland Clinic Journal of Medicine. 77, 12-19.
Trotter, R., Gallagher, R., \& Donoghue, J. (2011). Anxiety in patients undergoing percutaneous coronary interventions. Heart \& Lung. 40(3), 185-192.

Urden, L.D., Stacy, K.M., \& Lough, M.E., (2010). Critical care nursing : diagnosis and management, 6th edition. Kanada: Mosby.

Wang, W., Thompson, D.R., Chair, S.Y. \& Twinn, S.F. (2008). Chinese couples experiences during convalescence from a first heart attack: a focus group study. Journal of Advanced Nursing 61(3), 307-315. 